\title{
Fucosyllactose and L-fucose utilization of infant Bifidobacterium longum and Bifidobacterium kashiwanohense
}

\author{
Vera Bunesova ${ }^{1,2}$, Christophe Lacroix $^{1}$ and Clarissa Schwab ${ }^{1 *}$
}

\begin{abstract}
Background: Human milk oligosaccharides (HMOs) are one of the major glycan source of the infant gut microbiota. The two species that predominate the infant bifidobacteria community, Bifidobacterium longum subsp. infantis and Bifidobacterium bifidum, possess an arsenal of enzymes including a-fucosidases, sialidases, and $\beta$-galactosidases to metabolise HMOs. Recently bifidobacteria were obtained from the stool of six month old Kenyan infants including species such as Bifidobacterium kashiwanohense, and Bifidobacterium pseudolongum that are not frequently isolated from infant stool.

The aim of this study was to characterize HMOs utilization by these isolates. Strains were grown in presence of 2'-fucosyllactose (2'-FL), 3'-fucosyllactose (3'-FL), 3'-sialyl-lactose (3'-SL), 6'-sialyl-lactose (6'-SL), and Lacto-N-neotetraose $(\mathrm{LNnT})$. We further investigated metabolites formed during $L$-fucose and fucosyllactose utilization, and aimed to identify genes and pathways involved through genome comparison.

Results: Bifidobacterium longum subsp. infantis isolates, Bifidobacterium longum subsp. suis BSM11-5 and B. kashiwanohense strains grew in the presence of 2'-FL and 3'- FL. All B. longum isolates utilized the L-fucose moiety, while $B$. kashiwanohense accumulated L-fucose in the supernatant. 1,2-propanediol (1,2-PD) was the major metabolite from $L$-fucose fermentation, and was formed in equimolar amounts by $B$. longum isolates.

Alpha-fucosidases were detected in all strains that degraded fucosyllactose. B. longum subsp. infantis TPY11-2 harboured four a-fucosidases with 95-99\% similarity to the type strain. B. kashiwanohense DSM 21854 and PV20-2 possessed three and one a-fucosidase, respectively. The two a-fucosidases of B. longum subsp. suis were $78-80 \%$ similar to B. longum subsp. infantis and were highly similar to B. kashiwanohense a-fucosidases (95-99\%). The genomes of $B$. longum strains that were capable of utilizing $L$-fucose harboured two gene regions that encoded enzymes predicted to metabolize L-fucose to L-lactaldehyde, the precursor of 1,2-PD, via non-phosphorylated intermediates.

Conclusion: Here we observed that the ability to utilize fucosyllactose is a trait of various bifidobacteria species. For the first time, strains of $B$. longum subsp. infantis and an isolate of $B$. longum subsp. suis were shown to use L-fucose to form 1,2-PD. As 1,2-PD is a precursor for intestinal propionate formation, bifidobacterial L-fucose utilization may impact intestinal short chain fatty acid balance. A L-fucose utilization pathway for bifidobacteria is suggested.
\end{abstract}

Keywords: Bifidobacterium, HMOs, fucosyllactose, L-fucose, 1,2 propanediol

\footnotetext{
* Correspondence: clarissa.schwab@hest.ethz.ch

'Laboratory of Food Biotechnology, ETH Zurich, Institute of Food, Nutrition

and Health, Schmelzbergstrasse 7, Zurich, Switzerland

Full list of author information is available at the end of the article
}

\section{Biomed Central}

(c) The Author(s). 2016 Open Access This article is distributed under the terms of the Creative Commons Attribution 4.0 International License (http://creativecommons.org/licenses/by/4.0/), which permits unrestricted use, distribution, and reproduction in any medium, provided you give appropriate credit to the original author(s) and the source, provide a link to the Creative Commons license, and indicate if changes were made. The Creative Commons Public Domain Dedication waiver (http://creativecommons.org/publicdomain/zero/1.0/) applies to the data made available in this article, unless otherwise stated. 


\section{Background}

Bifidobacteria are universally distributed in organisms that raise offspring by parental care including mammals, birds and social insects. Bifidobacteria are highly specialized organisms in using non-digestible oligosaccharides and a major part of their genomes is devoted to the utilization of carbon sources [1-5]. The proportion of genes related to carbohydrate transport and metabolism is higher in bifidobacteria than in Bacteroides, which are also characterized by their ability to utilize a variety of polysaccharides [6]. Host-specific adaption in regard to carbohydrate degradation has been suggested [7, 8]. Adult species, such as Bifidobacterium adolescentis and Bifidobacterium longum subsp. longum, are well equipped to degrade plant derived polysaccharides [4, 9]. Infant species, such as Bifidobacterium longum subsp. infantis and Bifidobacterium bifidum, are adapted to utilize human milk oligosaccharides (HMOs), one of the major glycan sources of breast milk [3, 10-12]. Primary components of HMOs are D-glucose, D-galactose, L-fucose, $\mathrm{N}$-acetylglucosamine, and sialic acid. Lactose constitutes the reducing end, its galactose moiety can be fucosylated or sialylated to form $2^{\prime}$ - or $3^{\prime}$-fucosyllactose $\left(2^{\prime}-\mathrm{FL}\right.$ or $3^{\prime}$-FL) or $3^{\prime}$ - and $6^{\prime}$-sialyl-lactose $\left(3^{\prime}-\mathrm{SL}\right.$ or $\left.6^{\prime}-\mathrm{SL}\right)$. Lactose can also be elongated with units of $\mathrm{N}$-acetyllactosamine (Gal- $\beta 1-4 \mathrm{GlcNAc}$ ) with its simplest form being Lacto-N-neotetraose (LNnT) [13].

The degradation of HMOs relies on a complex network of extracellular solute binding proteins, transporters and intra- or extracellular glycosyl hydrolases $(\mathrm{GH})$. Both B. longum subsp. infantis and B. bifidum harbour several $\alpha$-fucosidase and sialidases, hexosaminidases, lacto- $\mathrm{N}$-biosidases, $\alpha$ - and $\beta$-galactosidases to degrade HMOs. B. longum subsp. infantis degrades HMOs intracellularly, while $B$. bifidum harvests HMOs extracellularly through the activity of membrane bound enzymes [3, 12]. Other species recovered from infant stool, such as Bifidobacterium breve, have a limited capacity to degrade HMOs, however, they can profit from cross-feeding of $\mathrm{HMO}$ constituents released by $B$. bifidum [14-16].

Bifidobacteria metabolize hexoses via the 'bifid shunt' with fructose-6-phosphoketolase being the key enzyme to theoretically yield $1.5 \mathrm{~mol}$ acetate, $1 \mathrm{~mol}$ lactate and 2.5 ATP from 1 mol glucose [17]. The ratios of lactate and acetate formed may vary with carbohydrate source and species, depending on whether the intermediate pyruvate is cleaved to acetyl phosphate and formate, or reduced to lactate [18]. Pentoses, such as xylose, are also fermented to lactate, acetate and possible formate [19]. There is little information available about bifidobacterial metabolism of desoxyhexoses, and rhamnose was not used by various species tested [6].
In a previous study, several Bifidobacterium strains were isolated from Kenyan infant stool, that were identified as B. longum, B. bifidum, B. breve, Bifidobacterium kashiwanohense, and Bifidobacterium pseudolongum [20]. B. kashiwanohense has only been isolated from a healthy Japanese infant [21] and from Kenyan anaemic infants [20]. B. pseudolongum has been frequently recovered from animal feces [22]. B. kashiwanohense, and $B$. pseudolongum are species not commonly associated with the infant bifidobacteria community, however, the presence of additional species in infant feces from developing countries, might reflect variations in diet and sanitary status. Little is known about the ability of these species to utilize HMOs.

Therefore it was the aim of this study to investigate HMO degradation by these newly obtained isolates. As we observed that beside $B$. longum subsp. infantis and $B$. bifidum, an isolate of $B$. longum subsp. suis, and strains of $B$. kashiwanohense were able to metabolise fucosyllactose, we further investigated metabolite formation during growth on L-fucose and fucosyllactose. Furthermore we analyzed genomes of the studied strains to elucidate possible genes and pathways involved in fucosyllactose degradation and L-fucose utilization through genome comparison.

\section{Methods}

\section{Bacterial strains}

Twenty-nine bifidobacterial strains were included in the initial HMO utilization screening (Table 1). Nineteen strains originated from stool samples of Kenyan infants [20] and ten reference strains were obtained from the Deutsche Sammlung von Mikroorganismen und Zellkulturen GmbH (DSMZ, Braunschweig, Germany, Table 1). Kenyan isolates that had been previously typed to species level were additionally characterized on subspecies level using the (partial) 16S rRNA gene as marker. Briefly, DNA was extracted from overnight cultures using the PrepMan ${ }^{\oplus}$ Ultra protocol for pure culture (Thermo Fisher Scientific, Reinach, Switzerland). PCR amplification of partial 16S rRNA genes was performed using universal primers $518 \mathrm{~F}$ (5'-CCAGCAGC CGCGGTAATACG-3') and 1391R (5'- GACGGGCGG TGTGTRCA-3'). PCR reaction mixtures $(25 \mu \mathrm{L})$ contained $12.5 \mu \mathrm{L}$ of $2 \times$ PCR MasterMix (Thermo Fisher Scientific), $0.2 \mu \mathrm{M}$ of primers (Microsynth AG, Balgach, Switzerland) and $1 \mu \mathrm{l}$ of template DNA. The cycling programme consisted of an initial denaturation of $5 \mathrm{~min}$ at $95{ }^{\circ} \mathrm{C}$, followed by 32 cycles of denaturation for $30 \mathrm{~s}$ at $95{ }^{\circ} \mathrm{C}$, annealing for $30 \mathrm{~s}$ at $52{ }^{\circ} \mathrm{C}$, and extension for $1 \mathrm{~min}$ at $72{ }^{\circ} \mathrm{C}$. Amplicons were sequenced by GATC Biotech (Konstanz, Germany).

For generation of phylogenetic trees, 16S rRNA gene sequences were aligned and cut using CLUSTALW 
Table 1 Strains used for $\mathrm{HMO}$ utilization screening

\begin{tabular}{|c|c|c|}
\hline Species & Strain code & Origin \\
\hline B. bifidum & DSM 20456 & stool of breast-fed infant \\
\hline B. bifidum & BRS26-2 & Kenyan infant stool, 6 m old \\
\hline B. bifidum & BSM2-3 & Kenyan infant stool, 6 m old \\
\hline B. bifidum & BRS-300 & Kenyan infant stool, 6 m old \\
\hline B. bifidum & BRS27-3 & Kenyan infant stool, 6 m old \\
\hline B. bifidum & BSM28-1 & Kenyan infant stool, 6 m old \\
\hline B. bifidum & TPY6-2 & Kenyan infant stool, 6 m old \\
\hline B. bifidum & DSM 20082 & intestine of adult \\
\hline B. bifidum & DSM 20215 & intestine of adult \\
\hline B. bifidum & DSM 20239 & stool of breast-fed infant \\
\hline B. breve & DSM 20213 & intestine of infant \\
\hline B. breve & TPY10-1 & Kenyan infant stool, 6 m old \\
\hline B. breve & TPY5-1 & Kenyan infant stool, 6 m old \\
\hline B. kashiwanohense & DSM 21854 & Japanese infant stool, 1.5 y old \\
\hline B. kashiwanohense & PV20-2 & Kenyan infant stool, 6 m old \\
\hline B. kashiwanohense & TPY11-1 & Kenyan infant stool, 6 m old \\
\hline B. kashiwanohense & BSM11-1 & Kenyan infant stool, 6 m old \\
\hline B. longum subsp. infantis & DSM 20088 & intestine of infant \\
\hline B. longum subsp. infantis & BRS8-2 & Kenyan infant stool, 6 m old \\
\hline B. longum subsp. infantis & TPY12-1 & Kenyan infant stool, 6 m old \\
\hline B. longum subsp. infantis & BRS8-1 & Kenyan infant stool, 6 m old \\
\hline B. longum subsp. infantis & TPY8-1 & Kenyan infant stool, 6 m old \\
\hline B. longum subsp. infantis & BSM12-2x & Kenyan infant stool, 6 m old \\
\hline B. longum subsp. longum & DSM 20219 & intestine of adult \\
\hline B. longum subsp. suis & BSM11-5 & Kenyan infant stool, 6 m old \\
\hline $\begin{array}{l}\text { B. pseudolongum subsp. } \\
\text { pseudolongum }\end{array}$ & DSM 20099 & pig faeces \\
\hline $\begin{array}{l}\text { B. pseudolongum subsp. } \\
\text { globosum }\end{array}$ & DSM 20092 & Rumen \\
\hline $\begin{array}{l}\text { B. pseudolongum subsp. } \\
\text { globosum }\end{array}$ & PV8-2 & Kenyan infant stool, $6 \mathrm{~m}$ old \\
\hline $\begin{array}{l}\text { B. pseudolongum subsp. } \\
\text { globosum }\end{array}$ & BSM8-1 & Kenyan infant stool, $6 \mathrm{~m}$ old \\
\hline
\end{tabular}

implemented in BioEdit Version 7. Phylogenetic analysis of partial $16 \mathrm{~S}$ rRNA gene sequences (772 bp) was performed using Maximum Likelihood Analysis implemented in MEGA6 [23], applying the Jones-TaylorThornton substitution model and default settings. Bootstrap support was calculated for 500 replicates, strains of Lactobacillus were applied as outgroup. Sequences are listed in the Additional file 1.

Based on partial 16S rRNA gene sequences, the Kenyan isolates were characterized as B. bifidum $(n=6), B$. breve $(n=2)$, Bifidobacterium kashiwanohense $(n=3)$, Bifidobacterium pseudolongum subsp. globosum $(n=2), B$. longum subsp. infantis $(n=5)$ and B. longum subsp. suis $(n=1)$ (Table 1).

\section{Growth conditions}

Bifidobacterium strains were routinely cultured at $37^{\circ} \mathrm{C}$ in Wilkins-Chalgren Anaerobe Broth (Oxoid, Basel, Switzerland) supplemented with soya peptone $\left(5 \mathrm{~g} \mathrm{~L}^{-1}\right.$, Oxoid), Tween 80 (1 $\mathrm{mL} \mathrm{L}^{-1}$, Sigma-Aldrich, Buchs, Switzerland), and fresh sterile filtered L-cysteine hydrochloride $\left(0.5 \mathrm{~g} \mathrm{~L}^{-1}\right.$, Sigma-Aldrich). Carbohydrate utilization profile of bifidobacteria was investigated in API 50CHL Medium (10 $\mathrm{g} \mathrm{L}^{-1}$ bovine/porcine origin polypeptone, $5 \mathrm{~g} \mathrm{~L}^{-1}$ yeast extract, $1 \mathrm{~mL}^{-1}$ Tween 80 , $2 \mathrm{~g} \mathrm{~L}^{-1}$ dipotassium phosphate, $5 \mathrm{~g} \mathrm{~L}^{-1}$ sodium acetate, $2 \mathrm{~g} \mathrm{~L}^{-1}$ di-ammonium citrate, $0.2 \mathrm{~g} \mathrm{~L}^{-1}$ magnesium sulphate heptahydrate, $0.05 \mathrm{~g} \mathrm{~L}^{-1}$ manganese sulphate monohydrate, $0.17 \mathrm{~g} \mathrm{~L}^{-1}$ bromocresol purple; BioMérieux, Genève, Switzerland). The $\mathrm{pH}$ of the API medium was adjusted to 7.5 to obtain a final $\mathrm{pH}$ of 7 after autoclaving at $121{ }^{\circ} \mathrm{C}$ for $15 \mathrm{~min}$. Carbohydrates (concentration as indicated) were filter sterilized and added after autoclaving. Fresh sterile filtered L-cysteine hydrochloride was always added before cultivation $\left(0.5 \mathrm{~g} \mathrm{~L}^{-1}\right)$. Glucose, lactose, and L-fucose were obtained from SigmaAldrich, 2'-fucosyllactose (2'-FL, Fuc $\alpha 1-2 \mathrm{Gal} \beta 1-4 \mathrm{Glc})$, 3 '-fucosyllactose (3'-FL, Fuc $\alpha 1-3 \mathrm{Gal} \beta 1-4 \mathrm{Glc}), 3$ '-sialyllactose (3'-SL, NeuAc $\alpha 2-3 G a l \beta 1-4 G l c), 6$ '-sialyl-lactose (6'-SL, NeuAc $\alpha 2-6 \mathrm{Gal} \beta 1-4 \mathrm{Glc}), \quad$ Lacto-N-neotetraose LNnT (Gal $\beta 1-4 G l c N a c \beta 1-3 G a l \beta 1-4 G l c)$ were donated by Glycom A/S (Lyngby, Denmark).

\section{Utilization of selected sugars and metabolite formation}

Isolates derived from $-80{ }^{\circ} \mathrm{C}$ stock cultures were streaked on supplemented Wilkins-Chalgren agar and were incubated anaerobically at $37^{\circ} \mathrm{C}$ for two days. Single colonies of each isolate were subsequently incubated twice in supplemented Wilkins-Chalgren broth $(10 \mathrm{ml}$, 1:10) at $37{ }^{\circ} \mathrm{C}$ for $20 \mathrm{~h}$. To obtain working cultures, the supernatant was removed from overnight cultures, cells were washed, and re-suspended in same volume of $50 \mathrm{mM}$ phosphate buffer, $\mathrm{pH} 6.5$ (PB).

The initial HMO utilization screening was conducted in 96-well microtiter plates. Cell suspensions $(20 \mu \mathrm{l})$ were added to $180 \mu \mathrm{l}$ carbohydrate supplemented API medium (2'-FL and $3^{\prime}-\mathrm{FL}: 4 \mathrm{mM}, 3^{\prime}-\mathrm{SL}$ and $6^{\prime}-\mathrm{SL}$ : $2 \mathrm{mM}$, LNnt: $1 \mathrm{mM}$; glucose: $6 \mathrm{mM}$; lactose: $3 \mathrm{mM}$ ). HMOs were also alone or supplied together (HMO mixture). Glucose and lactose were used to verify suitability of the assay. Strains were grown in independent triplicates under anaerobic condition (GENbag anaer; BioMérieux, Genève, Switzerland) at $37^{\circ} \mathrm{C}$ for $48 \mathrm{~h}$.

To investigate growth on fucosyllactose and L-fucose of selected strains, cell suspensions $(50 \mu \mathrm{l})$ were added to $950 \mu \mathrm{l}$ API medium supplied with $30 \mathrm{mM} \mathrm{L}$-fucose, $2^{\prime}$-FL, or 3 '-FL (28.0 and $27.0 \mathrm{mM}$, respectively). Strains were grown in independent triplicates under anaerobic condition at $37^{\circ} \mathrm{C}$ for $48 \mathrm{~h}$. 
L-fucose utilization and metabolite analysis using high performance liquid chromatography with refractive index detection (HPLC-RI)

L-fucose, lactate, acetate and 1,2-PD concentrations were determined using HPLC (Merck-Hitachi, Darmstadt, Germany) equipped with an Aminex HPX-87H column $(300 \times 7.8 \mathrm{~mm}$; BioRad, Cressier, Switzerland $)$ and a RI detector. Samples were centrifuged at $13000 \mathrm{~g}$ for $5 \mathrm{~min}$ at $4{ }^{\circ} \mathrm{C}$. Supernatants ( $40 \mu \mathrm{L}$ injection volume) were eluted with $10 \mathrm{mM} \mathrm{H}_{2} \mathrm{SO}_{4}$ at a flow rate of $0.6 \mathrm{ml} \mathrm{min}^{-1}$ at $40{ }^{\circ} \mathrm{C}$. L-fucose, lactate, acetate, and 1,2PD were quantified using external standards.

\section{Analysis of $\mathrm{HMO}$ degradation using high performance anion exchange chromatography with pulsed amperometric detection (HPAEC-PAD)}

HMO degradation was investigated using HPAEC-PAD, on Dionex IC3000 equipped with a CarbopacPA20 column (Thermo Fisher Scientific, Reinach, Switzerland) and an electrochemical detector with a gold electrode. Water (A), $200 \mathrm{mM} \mathrm{NaOH} \mathrm{(B),} \mathrm{and} 1 \mathrm{M} \mathrm{Na}$-acetate (C) were used as solvents at a flow rate of $0.25 \mathrm{~mL} \mathrm{~min}^{-1}$. For HMO separation, a gradient of: 0 min $30.4 \% \mathrm{~B}$, $1.3 \% \mathrm{C}, 22 \mathrm{~min} 30.4 \% \mathrm{~B}$, and $11.34 \% \mathrm{C}$ followed by washing and regeneration was applied. HMOs and Lfucose were identified using external standards.

\section{Genome sequencing}

DNA was isolated from overnight culture of $B$. longum subsp. infantis TPY12-1 and B. longum subsp. suis BSM11-5 using the FastDNA SPIN Kit for Soil (MP Biomedicals, France) including a bead-beating procedure for cell disruption. Genome libraries of B. longum subsp. infantis TPY12-1 were sequenced with an Illumina HiSeq 2500 to obtain paired-end reads of 2 x100 bp. Genome libraries of $B$. longum subsp. suis BSM11-5 were sequenced with an Illumina MiSeq to obtain paired-end reads of 2x150 bp. Sequencing was conducted at the Functional Genomic Center Zürich (FGCZ, Zürich, Switzerland).

\section{Genome assembly and annotation}

Genomes were assembled using Abyss v.1.9.0 for pairedend libraries implemented in Bio-Linux 8. The partial genomes were functionally annotated with RAST using default settings [24]. RAST annotations of genes of interest were verified using the BLAST tool implemented in RAST. Average nucleotide identity (ANI) was calculated using the online tool supplied by Rodriguez- $\mathrm{R}$ and Konstantinidis [25]. Carbohydrate-active enzymes were selectively confirmed based on similarity to the carbohydrate active enzyme (CAZy) database entries, and Pfam alignments implemented at the CAZymes Analysis Toolkit (CAT) [26]. Additionally, dbCAN was used for identification of carbohydrate active proteins which is based on a search for signature domains of every CAZyme family [27].

\section{Results and discussion Utilization of HMOs}

We investigated growth of 19 bifidobacterial isolates of Kenyan infants and 10 culture collection strains (Table 1) in the presence of individual HMOs: $2^{\prime}-\mathrm{FL}, 3^{\prime}-\mathrm{FL}, 3^{\prime}-$ SL, 6'-SL, and LNnT, and combined HMOs in API medium. All isolates were able to grow in the presence of glucose or lactose confirming the suitability of the assay (Table 2). Growth correlated with the degradation of the supplied HMOs as determined with HPAEC-PAD for selected strain-HMO combinations (Table 2).

B. longum subsp. infantis utilized of 2'-FL, 3'-FL, 3'$\mathrm{SL}$ and $\mathrm{LNnT}$ and degraded all HMOs when supplied together. B. bifidum grew in the presence of $2^{\prime}$-FL, $3{ }^{\prime}$-FL and LNnT and also utilized $3^{\prime}$-SL and $6^{\prime}$-SL in HMO mixtures confirming adaptation of both species to HMO utilization, as reported before [3, 12]. Strains of B. bifidum liberated L-fucose and a second degradation product (Fig. 1, peak y) in the supernatant when grown in the presence of fucosyllactose while L-fucose accumulation or the release of any other degradation intermediate was not observed for $B$. longum subsp. infantis strains [28] (Fig. 1).

All $B$. breve isolates were able to utilize $\mathrm{LNnT}$ as shown previously [15]. B. breve DSM 20213 also degraded 2'-FL and 3 '-FL when grown with HMO mixtures.

B. longum subsp. suis has not been shown to utilize of HMOs [11]. Here we identified an isolate $B$. longum subsp. suis BSM11-5 able to metabolize 3'-FL and 2'-FL (Fig. 1). L-fucose was not accumulated when $B$. longum subsp. suis BSM11-5 was grown with $4 \mathrm{mM}$ fucosyllactose.

Also, B. kashiwanohense DSM 21854 and the Kenyan isolates grew in the presence of 2'-FL and 3'-FL, thereby accumulating L-fucose and releasing compound $y$ (Fig. 1). The amount of L-fucose released by B. kashiwanohense isolates was only about $12 \%$ compared to the complete release of B. bifidum.

Strains of B. pseudolongum did not metabolize with any of the HMOs tested.

The ability to use fucosyllactose was thus identified as being a trait of several bifidobacteria species. B. longum subsp. suis and B. kashiwanohense have not considered infant bifidobacteria species, yet, the ability to utilize fucosyllactose points at adaptation to the infant gut.

\section{L-fucose metabolism of bifidobacteria}

Similar to B. bifidum, B. kashiwanohense excreted Lfucose into the supernatant [28]. L-fucose accumulation was not observed when $B$. longum subsp. infantis isolates and $B$. longum subsp. suis BSM 11-5 were grown in the presence of fucosyllactose. 
Table 2 Degradation of HMOs by selected strains

\begin{tabular}{|c|c|c|c|c|c|c|c|c|}
\hline Species & Strain & $\begin{array}{l}\mathrm{Glc} / \\
\mathrm{Lac}\end{array}$ & $2^{\prime}-\mathrm{FL}$ & 3'-FL & 3'-SL & 6'-SL & $\mathrm{LNnT}$ & HMO combinations \\
\hline \multirow{7}{*}{ B. bifidum } & $\begin{array}{l}\text { BRS26-2 } \\
\text { BSM2-3 }\end{array}$ & & \multirow{7}{*}{$\begin{array}{l}+ \\
+ \\
+\end{array}$} & \multirow{7}{*}{$\begin{array}{l}+ \\
+ \\
+\end{array}$} & \multirow{7}{*}{+} & \multirow{7}{*}{+} & \multirow{7}{*}{$\begin{array}{l}+ \\
+ \\
+\end{array}$} & \multirow[t]{3}{*}{ 2'-FL, 3'-FL, 3'-SL, 6'-SL, LNnT } \\
\hline & BRS-300 & & & & & & & \\
\hline & BRS27-3 & & & & & & & \\
\hline & BSM28-1 & & & & & & & 2'-FL, 3'-FL, 3'-SL, 6'-SL, LNnT \\
\hline & TPY6-2 & & & & & & & 2'-FL, 3'-FL, 3'-SL, 6'-SL, LNnT \\
\hline & DSM 20082 & & & & & & & 2'-FL, 3'-FL, 3'-SL, 6'-SL, LNnT \\
\hline & DSM 20215 & & & & & & & \\
\hline \multirow{3}{*}{ B. breve } & DSM 20213 & & - & 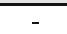 & \multirow[t]{3}{*}{-} & \multirow[t]{3}{*}{-} & - & 2'-FL, 3'-FL, LNnT \\
\hline & TPY10-1 & & \multirow[t]{2}{*}{-} & \multirow[t]{2}{*}{ - } & & & \multirow[t]{2}{*}{+} & LNnT \\
\hline & TPY5-1 & & & & & & & \\
\hline \multirow{4}{*}{$\begin{array}{l}\text { B. kashiwano- } \\
\text { hense }\end{array}$} & DSM 21854 & & \multirow{4}{*}{$\begin{array}{l}+ \\
+\end{array}$} & \multirow{4}{*}{$\begin{array}{l}+ \\
+\end{array}$} & \multirow{4}{*}{ - } & \multirow{4}{*}{-} & \multirow{4}{*}{$\begin{array}{l}- \\
-\end{array}$} & \multirow{4}{*}{$\begin{array}{l}\text { 2'-FL, 3'-FL } \\
\text { 2'-FL, 3'-FL }\end{array}$} \\
\hline & PV20-2 & & & & & & & \\
\hline & TPY11-1 & & & & & & & \\
\hline & BSM11-1 & & & & & & & \\
\hline \multirow{5}{*}{$\begin{array}{l}\text { B. longum } \\
\text { subsp. infantis }\end{array}$} & DSM 20088 & & \multirow{5}{*}{$\begin{array}{l}+ \\
+ \\
+\end{array}$} & \multirow{5}{*}{$\begin{array}{l}+ \\
+ \\
+\end{array}$} & - & \multirow{5}{*}{$\begin{array}{l}- \\
- \\
-\end{array}$} & \multirow{5}{*}{$\begin{array}{l}+ \\
+ \\
+\end{array}$} & \multirow{5}{*}{$\begin{array}{l}\text { 2'-FL, 3'-FL, 3'-SL, 6'-SL, LNnT } \\
\text { 2'-FL, 3'-FL, 3'-SL, 6'-SL, LNnT } \\
\text { 2'-FL, 3'-FL, 3'-SL, 6'-SL, LNnT }\end{array}$} \\
\hline & BRS8-2 & & & & + & & & \\
\hline & TPY12-1 & & & & + & & & \\
\hline & TPY8-1 & & & & & & & \\
\hline & BSM12-2x & & & & & & & \\
\hline $\begin{array}{l}\text { B. longum } \\
\text { subsp. longum }\end{array}$ & DSM 20219 & & - & - & - & - & - & - \\
\hline $\begin{array}{l}\text { B. longum } \\
\text { subsp. suis }\end{array}$ & BSM11-5 & & + & + & - & - & - & 2'-FL, 3'-FL \\
\hline \multicolumn{9}{|c|}{$\begin{array}{ll}\begin{array}{l}\text { B. } \\
\text { pseudolongum } \\
\text { subsp. }\end{array} & \text { DSM } 20099 \\
\text { pseudolongum } & \\
\end{array}$} \\
\hline$B$ & DSM 20092 & & & & & & & \\
\hline pseudolongum & BSM8-1 & & - & - & - & - & - & - \\
\hline globosum & PV8-2 & & & & & & & \\
\hline
\end{tabular}

Growth is indicated by grey shading. Degradation of HMOs of selected samples was investigated by HPAEC-PAD

Plus (+) indicates degradation of $\mathrm{HMO}$ tested, minus (-) no degradation

$\mathrm{HMOs}$ that were used during growth in the presence of HMO combinations (2'-FL, $\left.3^{\prime}-\mathrm{FL}, 3^{\prime}-\mathrm{SL}, 6^{\prime}-\mathrm{SL}, \mathrm{LNnT}\right)$ are indicated in the respective column

Several clostridia and E. coli are capable of metabolizing L-fucose to 1,2 propanediol (1,2-PD) [29-33]. To investigate whether bifidobacteria are able to form 1,2-PD from L-fucose, B. longum subsp. infantis DSM 20088 and TPY12-1, B. longum subsp. suis BSM11-5, and B. kashiwanohense DSM 21854 were cultivated in API medium supplied with $30 \mathrm{mM}$ L-fucose. As growth with L-fucose as sole carbohydrate source was unreliable, trace amounts of glucose $(0.4 \mathrm{mM})$ were added to enable initial growth. When glucose was present, L-fucose was partially used and equimolar amounts of 1,2-PD were formed by the two strains of $B$. longum subsp. infantis, and by B. longum subsp. suis BSM11-5 (Table 3). B. longum subsp. suis BSM11-5 also formed equimolar amounts of acetate (Table 3). In contrast B. kashiwanohense DSM 21854 did not grow with L-fucose and trace amounts of glucose.

We also investigated whether 1,2-PD was formed from $3^{\prime}$-FL and $2^{\prime}$-FL (27 and $28 \mathrm{mM}$, respectively) (Table 4). In the presence of $2^{\prime}-\mathrm{FL}$ and $3^{\prime}-\mathrm{FL}, B$. longum subsp. infantis DSM 20088 produced a lactate:acetate ratio of $2: 3$ as expected of the metabolism of hexoses through the bifid shunt [17] in addition, this strain produced 1,2PD (Table 4).

In contrast, the ratio of lactate:acetate of $B$. longum subsp. suis BSM 11-5 grown with $2^{\prime}$-FL and 3 '-FL was approx. 1:1 and 1:3 respectively. B. longum subsp. suis BSM 11-5 synthesized 1,2-PD mainly from 3'-FL, and accumulated $5 \mathrm{mM}$ L-fucose when grown in the presence of 2 '-FL. L-fucose might have been accumulated during growth in the presence of $28 \mathrm{mM} \mathrm{2'-FL} \mathrm{as} \mathrm{glu-}$ cose and galactose became also available after fucosyllactose degradation.

B. kashiwanohense DSM 21854 grew in the presence of 2'-FL and 3'FL and accumulated approximately $10 \mathrm{mM}$ L-fucose but did not produce any 1,2-PD (Table 4). The ratio of lactate:acetate was approx. 1:2.

B. longum subsp. infantis degrades HMOs internally $[3,34]$. The gap in substrate consumption, L-fucose release and/or 1,2-PD formation observed for B. longum 


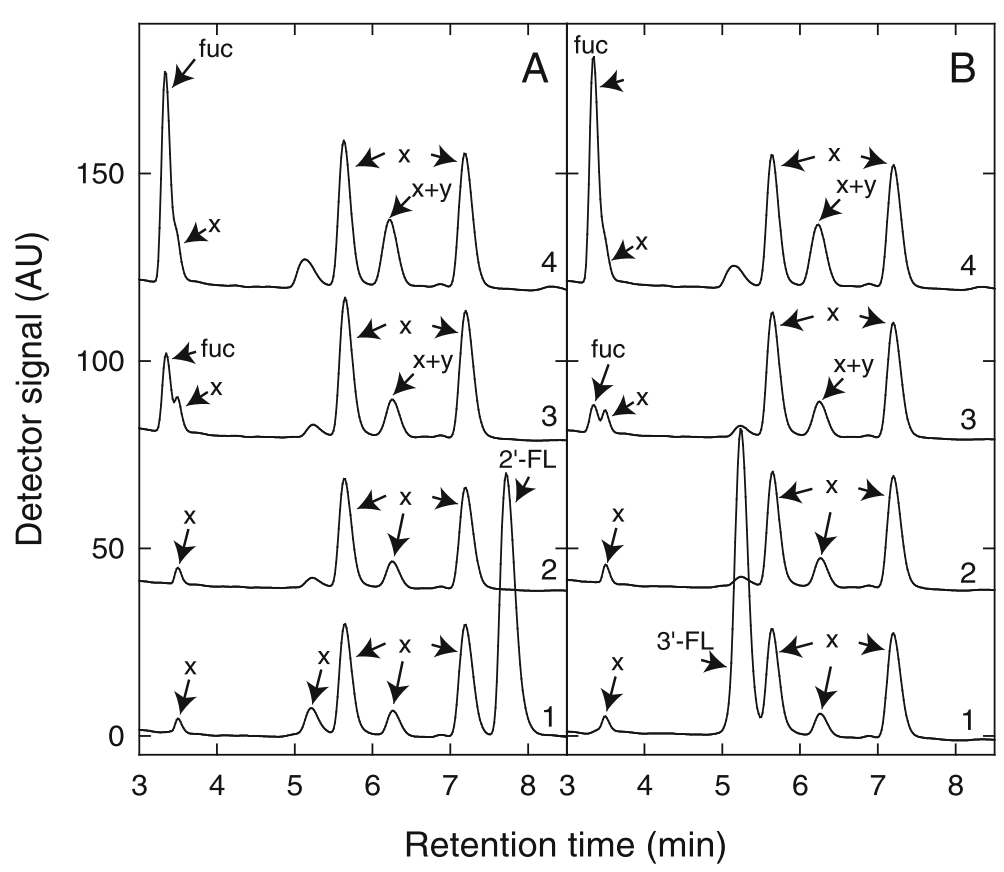

Fig. 1 Degradation of 2'-FL (a) and 3'-FL (b) and accumulation of L-fucose. Shown are (1) unfermented control, (2) B. longum subsp. infantis DSM 20088, (3) B. kashiwanohense PV20-2, and (4) B. bifidum BSM28-1 as representatives of B. longum, B. kashiwanohense and B. bifidum isolates investigated. $x$, undefined media components; $y$, intermediate degradation compound of fucosyllactose metabolism; fuc, L-fucose

subsp. infantis and B. longum subsp. suis might be due to the intracellular which were not released in the supernatant. In contrast, fucose and an additional compound were detected in supernatants of B. bifidum which harvests fucosyllactose extracellularly [28, 34].

We here identified 1,2-PD as a metabolite of bifidobacteria fucosyllactose respective L-fucose degradation. L-fucose derived 1,2-PD can be further metabolized to propionate and propanol by other gut microbes such as Eubacterium hallii $[35,36]$. It was estimated that in adults approximately $30 \%$ of propionate might derive from 1,2-PD, but no data exists for infants [36, 37]. Nevertheless, the bifidobacterial formation of lactate and 1,2-PD as precursors of short chain fatty acids butyrate and propionate, respectively, contributes to the trophic interactions of the infant gut microbiota [38].

\section{Genome comparison}

Strains of B. longum subsp. infantis, and B. longum subsp. suis used the L-fucose moiety of $2^{\prime}$-FL and $3^{\prime}-\mathrm{FL}$ to form 1,2-PD, but the enzymatic pathways of bifidobacterial L-fucose metabolism are not known [3]. To further elucidate putative fucosyllactose and L-fucose utilization pathways, we generated draft genomes of $B$. longum subsp. infantis TPY12-1 and B. longum subsp. suis BSM11-5 for comparing genome data with type strain B. longum subsp. infantis DSM 20088 [3], and to B. kashiwanohense DSM 21854 [39] and PV-20 [40]. Abyss assembly yielded 72 and 105 contigs ( $>500 \mathrm{bp}$ ) from 8.1 to 1.9 Mio reads for $B$. longum subsp. suis BSM11-5 and B. longum subsp. infantis TPY12-1, respectively (Table 5 ). For $B$. longum subsp. suis BSM11-5, the N50 was of $135.581 \mathrm{bp}$, and the largest contig had

Table 3 L-fucose utilization and metabolite formation

\begin{tabular}{lllll}
\hline Strain & $\begin{array}{l}\text { Substrate used } \\
\text { L-fucose }(\mathrm{mM})\end{array}$ & \multicolumn{3}{l}{ Metabolite formed } \\
\cline { 3 - 5 } & $-3.4 \pm 0.3$ & $4.0 \pm 0.5$ & acetate $(\mathrm{mM})$ & $1,2-\mathrm{PD}(\mathrm{mM})$ \\
\hline B. longum subsp. infantis DSM 20088 & $-6.2 \pm 0.8$ & $3.7 \pm 3.8$ & $1.3 \pm 1.3$ & $3.9 \pm 0.8$ \\
B. longum subsp. infantis TPY12-1 & $-11.4 \pm 2.9$ & $5.6 \pm 2.2$ & $1.6 \pm 2.2$ & $1.3 \pm 0.4$ \\
B. longum subsp. suis BSM11-5 & 0 & $4.0 \pm 1.7$ & $10.5 \pm 2.7$ & $10.0 \pm 3.1$ \\
B. kashiwanohense DSM 21854 & 0 & $3.5 \pm 1.4$ & 0 \\
\hline
\end{tabular}

Strains were grown in API medium with L-fucose $(30 \mathrm{mM})$ and $0.4 \mathrm{mM}$ glucose as carbohydrate sources for $48 \mathrm{~h}$. L-fucose, lactate, acetate, and 1,2-PD were analysed with HPLC-RI $(n=3)$ 
Table 4 Fucosyllactose utilization, metabolite formation and L-fucose accumulation

\begin{tabular}{|c|c|c|c|c|c|c|}
\hline \multirow[t]{2}{*}{ Strain } & \multicolumn{2}{|l|}{ Substrate } & \multicolumn{4}{|c|}{ Metabolite formed } \\
\hline & Supplied & used (mM) & L-fucose (mM) & lactate $(\mathrm{mM})$ & acetate $(\mathrm{mM})$ & 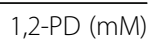 \\
\hline \multirow[t]{2}{*}{ B. longum subsp. infantis DSM 20088} & $2^{\prime}-\mathrm{FL}$ & $-24.0 \pm 4.4$ & $0.7 \pm 1.1$ & $18.0 \pm 2.7$ & $29.0 \pm 6.6$ & $6.8 \pm 1.5$ \\
\hline & $3^{\prime}-\mathrm{FL}$ & $-23.6 \pm 0.2$ & 0 & $14.0 \pm 0.8$ & $23.5 \pm 0.7$ & $7.1 \pm 0.2$ \\
\hline \multirow[t]{2}{*}{ B. longum subsp. suis BSM11-5 } & $2^{\prime}-\mathrm{FL}$ & $-20.1 \pm 4.1$ & $5.2 \pm 0.7$ & $13.1 \pm 4.4$ & $13.3 \pm 4.8$ & $3.2 \pm 0.4$ \\
\hline & $3^{\prime}-\mathrm{FL}$ & $-24.7 \pm 3.9$ & $0.5 \pm 0.5$ & $10.3 \pm 1.3$ & $27.3 \pm 7.0$ & $7.5 \pm 1.2$ \\
\hline \multirow[t]{2}{*}{ B. kashiwanohense DSM 21854} & $2^{\prime}-\mathrm{FL}$ & $-25.0 \pm 0.2$ & $10.5 \pm 0.2$ & $12.3 \pm 1.0$ & $18.2 \pm 1.3$ & 0 \\
\hline & $3^{\prime}-\mathrm{FL}$ & $-19.9 \pm 2.1$ & $10.2 \pm 0.1$ & $11.3 \pm 0.8$ & $19.2 \pm 1.1$ & 0 \\
\hline
\end{tabular}

Strains were grown with 3'-FL or 2'-FL (28 and $27 \mathrm{mM}$. respectively) as sole carbohydrate source for $48 \mathrm{~h}$. 2'-FL and 3'-FL concentrations were determined with HPAEC-PAD, L-fucose, lactate, acetate, and 1,2-PD were analysed with HPLC-RI $(n=3)$

298.614 bp. The N50 of B. longum subsp. infantis TPY12-1 was 94.696 bp with the largest contigs of 163.755 bp. ANI of B. longum subsp. infantis TPY12-1 compared to type strain was $98.4 \%$. B. longum subsp. suis type strain DSM 20211 and BSM11-5 had an ANI of $98.3 \%$, whereas ANI of B. longum subsp. suis BSM11-5 and B. longum subsp. infantis DSM 20088, or B. longum subsp. longum DSM 20019 was 96.6 and $96.7 \%$, respectively, confirming phylogenetic placement of this isolate based on partial 16S rRNA gene analysis (Additional file 1: Figure S1).

Lo Cascio et al. [11] defined six gene regions related to gut adaption and HMO utilization which distinguished subspecies B. longum subsp. longum and infantis (urease, $\mathrm{H} 1-\mathrm{H} 5$ ). All six regions were present in the genome of $B$. longum subsp. infantis TPY12-1. B. longum subsp. suis BSM11-5 possessed an urea operon similar to B. longum subsp. infantis. This strain also harboured the LNB region (H5) as reported before for two B. longum subsp. suis isolates, and possessed parts of HMO utilization operon $\mathrm{H} 1$. However, B. longum subsp. suis BSM11-5 lacked additional $\alpha$-fucosidase and sialidase containing gene regions $\mathrm{H} 2-\mathrm{H} 4$. Surprisingly, B. kashiwanohense DSM 21854 and PV20-2 also partly harboured $\mathrm{H} 1$ (Fig. 3), and B. kashiwanohense PV20-2 possessed an urea uptake and degradation operon with $>90 \%$ homology to B. longum subsp. infantis DSM 20088.
Presence of a-fucosidase encoding genes in $B$. longum subsp. infantis TPY 12-1, B. longum subsp. suis BSM11-5, and B. kashiwanohense

Alpha-fucosidases, which catalyze the release of $\alpha-1-2$, $\alpha-$ $1-3$, and $\alpha-1-4$ linked fucose, are assigned to $\mathrm{GH}$ families 29 and 95 (GH29 and GH95). B. longum subsp. infantis DSM 20088 harbours four $\alpha$-fucosidases: BLON_0248 (GH29), BLON_0426 (GH29), BLON_2335 (GH95) and BLON_2336 (GH29). B. longum subsp. infantis DSM 20088 also possesses BLON_0346, which is assigned to GH42 but can degrade Fuca1-2Gal [41]. Paralogs BLON_0248 and BLON_0426 are $95 \%$ identical [41].

BlastP was used to identify homologues of the $\alpha$ fucosidases of $B$. longum subsp. infantis DSM 20088 in the genomes of $B$. longum subsp. infantis TPY12-1, $B$. longum subsp. suis BSM11-5 and the two B. kashiwanohense strains (Table 6).

B. longum subsp. infantis TPY12-1 possessed homologues of BLON_0248/BLON_0426, BLON_0346, BLON_2335, and BLON_2336. B. longum subsp. suis BSM11-5 harboured two $\alpha$-fucosidases highly similar to BLON_2335, and BLON_2336. B. kashiwanohense DSM 21854 and PV20-2 possessed three and one $\alpha$-fucosidases, respectively, with high homology ( $>78 \%$ ) to $B$. longum subsp. infantis DSM 20088. BBKW_1714 of B. kashiwanohense DSM 21584 was flanked by a mobile element and was $100 \%$ identical to BLON_0248/BLON_0426. B. longum subsp. suis BSM11-5, and B. kashiwanohense $\alpha$-fucosidases were

Table 5 Genome characteristics of B. longum subsp. infantis, suis and B. kashiwanohense strains used in this study

\begin{tabular}{lllclll}
\hline Strain & ID & Contigs & $\begin{array}{l}\text { (Predicted) } \\
\text { Genome size (Mbp) }\end{array}$ & GC-content & Coding sequences (RNAs) & Reference \\
\hline B. longum subsp. infantis & DSM 20088 & 1 & 2.83 & 59.9 & $2432(91)$ & [3] \\
& TPY12-1 & 105 & 2.65 & 59.9 & $2371(58)$ & This study \\
B. longum subsp. suis & BSM11-5 & 72 & 2.61 & 59.9 & $2206(61)$ & This study \\
B. kashiwanohense & DSM 21854 & 1 & 2.34 & 56.3 & 1945 & [39] \\
& PV20-2 & 1 & 2.37 & 56.1 & $1875(63)$ & [40] \\
\hline
\end{tabular}


Table 6 Presence of a-fucosidases

\begin{tabular}{llllll}
\hline & Strain & & & \\
\cline { 2 - 5 } & $\begin{array}{l}\text { B. longum subsp. } \\
\text { infantis DSM 20088 }\end{array}$ & $\begin{array}{l}\text { B. longum subsp. } \\
\text { infantis TPY11-1 }\end{array}$ & $\begin{array}{l}\text { B. longum subsp. suis } \\
\text { BSM 11-5 }\end{array}$ & $\begin{array}{l}\text { B. kashiwanohense } \\
\text { DSM 21854 }\end{array}$ & $\begin{array}{l}\text { B. kashiwanohense } \\
\text { PV20-2 }\end{array}$ \\
\hline Alpha-fucosidase & BLON_0248 & $155(99 \%, 446 / 449)$ & - & $\begin{array}{l}\text { BBKW_1714 } \\
(100 \%, 449 / 449)\end{array}$ \\
& BLON_0426 & - & - & - \\
BLON_0346 & $2339(97 \%, 247 / 254)$ & - & - & - \\
& BLON_2335 & $2028(98 \%, 769 / 782)$ & $229(78 \%, 607 / 783)$ & $\begin{array}{l}\text { BBKW_1831 } \\
(77 \%, 606 / 783)\end{array}$ & AH68_10220 \\
& & & BBKW_1832 $\%, 607 / 783)$ \\
$(82 \%, 417 / 478)$ & - \\
\hline
\end{tabular}

Alpha-fucosidases of $B$. longum subsp. infantis DSM 20088 and homologues present in the genomes of $B$. longum subsp. infantis TPY12-1, B. longum subsp. suis BSM11-5, and B. kashiwanohense strains

${ }^{\mathrm{a}} \mathrm{A}$ recent transcriptomic study investigated gene expression of $B$. longum subsp. infantis DSM 20088 in the presence of $2^{\prime}-\mathrm{FL}$ and $3^{\prime}-\mathrm{FL}$, a-fucosidases that were overexpressed are indicated [34]

(-) not present, in brackets; similarity with B. longum subsp. infantis DSM 20088 a-fucosidases in AA

highly similar to each other (98-99 \%) (Table 6). A search for conserved protein domains of every CAZyme family [27], identified no further GH29 or GH95 the genomes of B. longum subsp. infantis TPY12-1, B. longum subsp. suis BSM11-5, and B. kashiwanohense DSM 21854 and PV20-2.

Heterologously expressed BLON_0248, BLON_426, and BLON_0346 previously showed no activity on 2'-FL and 3'-FL [41], and BLON_2336 degraded only 3'-FL. BLON_2335 was able to degrade $2^{\prime}$-FL and $3{ }^{\prime}$-FL [41] and homologues of BLON_2335 were present B. longum and $B$. kashiwanohense strains analysed here.

$B$. kashiwanohense has been rarely isolated infant stool and not yet from adults $[20,21]$, while $B$. longum subsp. infantis is considered an infant bifidobacteria species due to its adaption to degrade HMOs. The presence of highly similar genetic elements (region $\mathrm{H} 1, \alpha$-fucosidases, urease operon) flanked by mobile elements indicate possible gene transfer between $B$. longum and B. kashiwanohense which suggests a co-evolutionary history between the two species that adapted B. kashiwanohense to the infant gut environment.

\section{Putative L-fucose degradation pathways in B. longum subsp. infantis, and $B$. longum subsp. suis BSM11-5}

Strains of B. longum subsp. infantis, and B. longum subsp. suis BSM $11-5$ used the L-fucose moiety of $2^{\prime}$-FL and 3 '-FL to form 1,2-PD. However, the enzymatic pathway of Bifidobacterium sp. L-fucose metabolism is not known. Microorganisms can metabolize desoxyhexoses such as fucose by two pathways involving phosphorylated and non-phosphorylated intermediates (Fig. 2). For example in E. coli, Roseburia inulivorans, and Lactobacillus rhamnosus fucose isomerase FucI, fucose kinase FucK and fucose aldolase FucA are responsible for L-fucose to L-lactaldehyde transformation under anaerobic conditions [29, 30, 42]. L-rhamnose is metabolized via a similar enzymatic pathway [30]. For Campylobacter jejuni and Xanthomonas campestris, another pathway has been described with non-phosphorylated intermediates $[43,44]$. Here L-fucose is internalized via the activity of a permease and metabolized to L-lactate and pyruvate by the activity of L-fucose mutarotase, L-fucose dehydrogenase, L-fuconolactone hydrolase, L-fuconate dehydratase, L-2-keto-3-deoxy-fuconate hydrolase, and a L-2,4-diketo3-deoxy-fuconate hydrolase (Fig. 2, [43, 44]).

B. longum subsp. infantis DSM 20088 lacks the genes encoding proteins to use fucose via phosphorylation [3]. FucI, FucK and FucA were also not detected in the other genomes analysed here. To investigate whether bifidobacteria might utilize L-fucose similar to $X$. campestris, we searched for the corresponding proteins of $X$. campestris in bifidobacteria genomes using BlastP, and also collected enzymes related to fucose metabolism that were annotated by RAST.

B. longum subsp. infantis DSM 20088 and TPY11-1, and B. longum subsp. suis BSM11-5 possessed putative L-fucose dehydrogenases, a L-fuconolactone hydrolase, L-fuconate dehydratases, L-2-keto-3-deoxy-fuconate hydrolases, and a L-2,4-diketo-3-deoxy-fuconate hydrolase with homologies ranging from 24 to $56 \%$ AA similarity to the enzymes of the $X$. campestris (Table 7). A homologue of the L-fucose mutarotase of $X$. campestris (XCC4070) was not detected; however, putative L-fucose mutarotases encompassing the conserved RbsD/FucU transport protein family domain were identified by RAST (Table 7).

The majority of genes was located on two genomic regions (Fig. 3). In contrast, in $X$. campestris all responsible genes were located on an operon XCC4065XCC4070 [44]. Region 1 encompassed a L-fucose mutarotase, a L-2-keto-3-deoxy-fuconate hydrolase, and a L-fuconate dehydratase (Fig. 3). The gene cluster of region 1 also contained genes encoding the $\alpha$ fucosidases BLON_2335 and BLON_2336 and is part of 


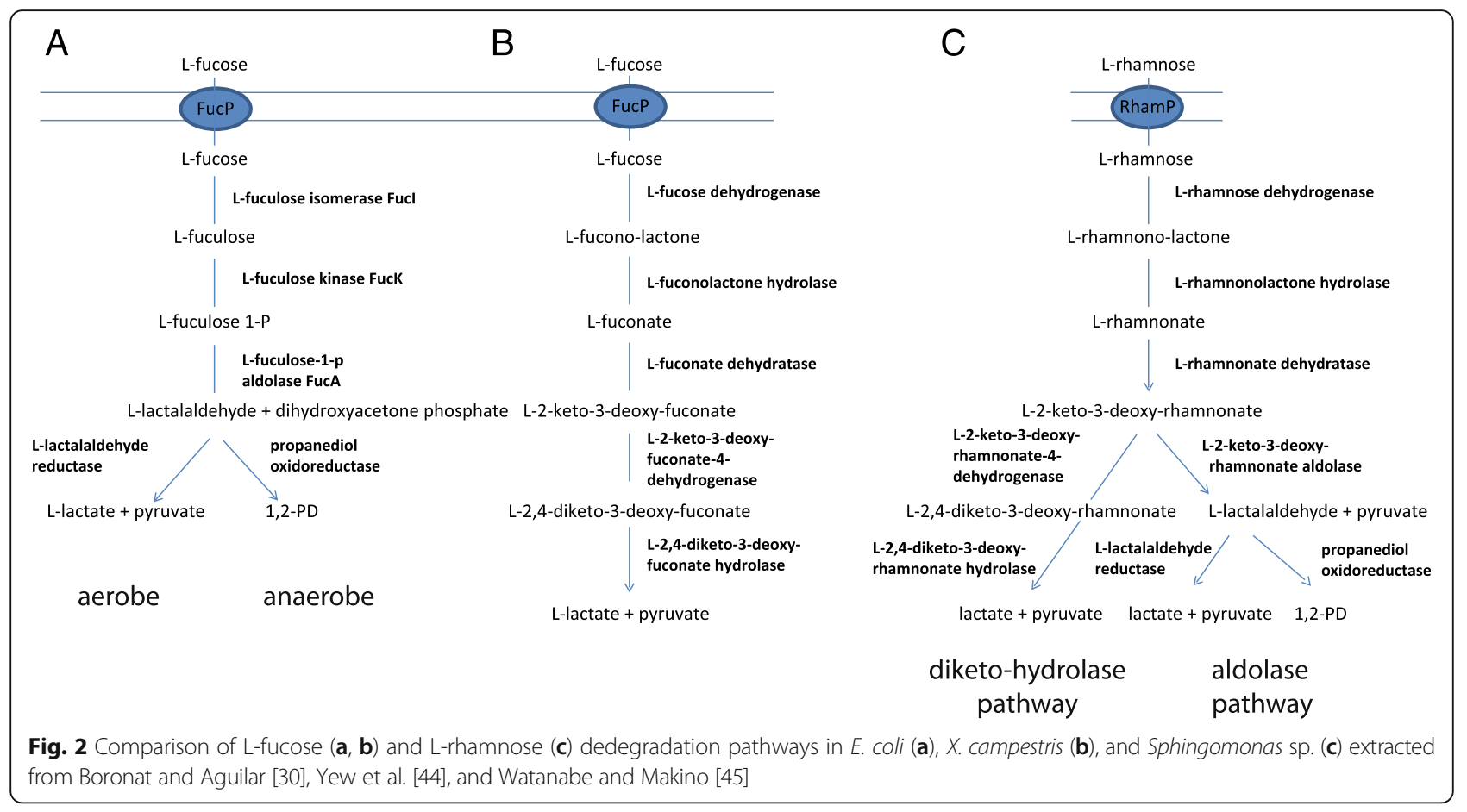

Table 7 Identification of B. longum and B. kashiwanohense genes related to L-fucose metabolism

\begin{tabular}{|c|c|c|c|c|c|c|c|}
\hline \multirow[b]{2}{*}{ Enzyme } & \multirow[b]{2}{*}{$\begin{array}{c}\text { Homologue of } \\
X . \text { campestris }\end{array}$} & \multicolumn{6}{|c|}{ Strain } \\
\hline & & $\begin{array}{c}\text { RAST } \\
\text { annotation }\end{array}$ & $\begin{array}{l}\text { B. longum subsp. } \\
\text { infantis DSM } \\
20088 \\
\end{array}$ & $\begin{array}{c}\text { B. longum } \\
\text { subsp. infantis } \\
\text { TPY12-1 }\end{array}$ & $\begin{array}{l}\text { B. longum } \\
\text { subsp. suis } \\
\text { BSM11-5 }\end{array}$ & $\begin{array}{c}B . \\
\text { kashiwanohense } \\
\text { DSM } 21854\end{array}$ & $\begin{array}{c}B . \\
\text { kashiwanohense } \\
\text { PV20-2 }\end{array}$ \\
\hline $\begin{array}{l}\text { Fucose } \\
\text { permease }\end{array}$ & & $\begin{array}{l}\text { Transporter, major } \\
\text { facilitator family } \\
\text { protein }\end{array}$ & BLON_2307 ${ }^{+}$ & 1988 & 1299 & - & - \\
\hline \multirow{2}{*}{$\begin{array}{l}\text { L-fucose } \\
\text { dehydrogenase }\end{array}$} & \multirow{2}{*}{ XCC0141_4065 } & $\begin{array}{l}\text { Aldo/keto } \\
\text { reductases }\end{array}$ & $\begin{array}{c}\text { BLON_0820 } \\
\left(28 \%, 6 \overline{4}, 1 \mathrm{e}^{-12}\right)\end{array}$ & $\begin{array}{c}267 \\
\left(32 \%, 64,4 \mathrm{e}^{-12}\right)\end{array}$ & $\begin{array}{c}1597 \\
\left(32 \%, 62,5 \mathrm{e}^{-12}\right)\end{array}$ & $\begin{array}{l}\text { BBKW_0110 } \\
\left(26 \%, 65,3 \mathrm{e}^{-13}\right)\end{array}$ & $\begin{array}{l}\text { AH68_01290 } \\
\left(24 \%, \overline{43}, 3 \mathrm{e}^{-07}\right)\end{array}$ \\
\hline & & $\begin{array}{l}\text { Predicted } \\
\text { oxidoreductases }\end{array}$ & $\begin{array}{l}\text { BLON_0406 } \\
\left(24 \%, 48,2 \mathrm{e}^{-07}\right)\end{array}$ & $\begin{array}{c}122 \\
\left(24 \%, 47,3 \mathrm{e}^{-07}\right) \\
\end{array}$ & $\begin{array}{c}290 \\
\left(21 \%, 45,2 \mathrm{e}^{-06}\right) \\
\end{array}$ & - & - \\
\hline $\begin{array}{l}\text { L-fuconolactone } \\
\text { hydrolase }\end{array}$ & XCC0141_4066 & $\begin{array}{l}\text { Hypothetical } \\
\text { protein }\end{array}$ & $\begin{array}{l}\text { BLON_2306 } \\
\left(24 \%, 45,1 \mathrm{e}^{-06}\right)\end{array}$ & $\begin{array}{c}1987 \\
\left(24 \%, 47,2 \mathrm{e}^{-07}\right)\end{array}$ & $\begin{array}{c}1298 \\
\left(23 \%, 45, \mathrm{e}^{-06}\right)\end{array}$ & $\begin{array}{l}\text { BBKW_1835 } \\
\left(28 \%, 50,3 \mathrm{e}^{-08}\right)\end{array}$ & $\begin{array}{l}\text { AH68_10230 } \\
\left(27 \%, \overline{50}, 3 \mathrm{e}^{-08}\right)\end{array}$ \\
\hline \multirow{2}{*}{$\begin{array}{l}\text { L-fuconate } \\
\text { dehydratase }\end{array}$} & \multirow{2}{*}{ XCC0141_4069 } & \multirow{2}{*}{$\begin{array}{l}\text { L-fuconate } \\
\text { dehydratase }\end{array}$} & $\begin{array}{l}\text { BLON 2340 } \\
\left(56 \%, 506, \mathrm{e}^{-180}\right)\end{array}$ & $\begin{array}{c}2033 \\
\left(56 \%, 506, \mathrm{e}^{-180}\right)\end{array}$ & $\begin{array}{c}224 \\
\left(56 \%, 506, \mathrm{e}^{-180}\right)\end{array}$ & $\begin{array}{c}\text { BBKW_1837 } \\
\left(56 \%, 504, \mathrm{e}^{-179}\right)\end{array}$ & $\begin{array}{c}\text { AH68 10240 } \\
\left(56 \%, 504, \mathrm{e}^{-179}\right)\end{array}$ \\
\hline & & & $\begin{array}{l}\text { BLON 2309 } \\
\left(54 \%, 488, \mathrm{e}^{-173}\right) \\
\end{array}$ & $\begin{array}{c}1990 \\
\left(54 \%, 488, \mathrm{e}^{-173}\right) \\
\end{array}$ & $\begin{array}{c}1301 \\
\left(53 \%, 488, \mathrm{e}^{-173}\right) \\
\end{array}$ & & 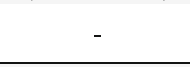 \\
\hline \multirow{2}{*}{$\begin{array}{l}\text { L-2-keto-3- } \\
\text { deoxy-fuconate- } \\
\text { 4- } \\
\text { dehydrogenase }\end{array}$} & \multirow{2}{*}{ XCC0141_4067 } & \multirow{2}{*}{$\begin{array}{l}\text { Dehydrogenase } \\
\text { clustered with L- } \\
\text { fuconate utilization } \\
\text { genes }\end{array}$} & $\begin{array}{l}\text { BLON_2308 } \\
\left(29 \%, 88,2^{-2.21}\right)\end{array}$ & $\begin{array}{c}1989 \\
\left(29 \% .88,2^{\mathrm{c}-21}\right)\end{array}$ & $\begin{array}{c}1300 \\
\left(30 \%, 93,2^{\mathrm{c}-23}\right)\end{array}$ & $\begin{array}{l}\text { BBKW_1136 } \\
\left(32 \%, 98,4^{-25}\right)\end{array}$ & $\begin{array}{l}\text { AH68 } 10235 \\
\left(29 \%, 82,1^{\mathrm{e}-19}\right)\end{array}$ \\
\hline & & & $\begin{array}{l}\text { BLON_2339+ } \\
\left(29 \%, 82,4 \mathrm{e}^{-19}\right)\end{array}$ & $\begin{array}{c}2032 \\
\left(29 \%, 79,3 \mathrm{e}^{-18}\right)\end{array}$ & $\begin{array}{c}225 \\
\left(30 \%, 84,4^{\mathrm{c}-25}\right)\end{array}$ & $\begin{array}{l}\text { BBKW_1836 } \\
\left(30 \%, 8 \overline{4}, 3^{\mathrm{c}-20}\right)\end{array}$ & $\begin{array}{l}\text { AH68 } 04495 \\
\left(31 \%, \overline{75}, 7^{\mathrm{c}-17}\right)\end{array}$ \\
\hline $\begin{array}{l}\text { L-2.4-diketo-3- } \\
\text { deoxy-fuconate } \\
\text { hydrolase }\end{array}$ & XCC0141_4068 & $\begin{array}{l}\text { Fumarylaceto- } \\
\text { acetate hydrolase } \\
\text { family protein }\end{array}$ & $\begin{array}{c}\text { BLON } 2375 \\
\left(34 \%, 124,2 \mathrm{e}^{-35}\right)\end{array}$ & $\begin{array}{c}310 \\
\left(34 \%, 123,7 \mathrm{e}^{-35}\right)\end{array}$ & $\begin{array}{c}682 \\
\left(34 \%, 123,7 \mathrm{e}^{-35}\right)\end{array}$ & $\begin{array}{l}\text { BBKW_1708 } \\
\left(34 \%, 130,2^{-\cdot-37}\right)\end{array}$ & $\begin{array}{l}\text { AH68 } 09145 \\
\left(34 \%, 129,5^{-37}\right)\end{array}$ \\
\hline \multirow[t]{3}{*}{$\begin{array}{l}\text { L-fucose } \\
\text { mutarotase }\end{array}$} & \multirow[t]{3}{*}{ XCC0141_4070 } & & - & - & - & - & - \\
\hline & & \multirow{2}{*}{$\begin{array}{l}\text { L-fucose } \\
\text { mutarotase }\end{array}$} & BLON_2337 ${ }^{+}$ & 2030 & 226 & $\begin{array}{c}\text { BBKW_1833 } \\
\text { (partial) }\end{array}$ & - \\
\hline & & & BLON_2305 & 1986 & - & & - \\
\hline
\end{tabular}

L-fucose related genes were identified by blastP search of homologous proteins of $X$. campestris, and by annotation by RAST using default settings. Shown are gene ID and in brackets bit scores and $e$-values of the obtained hits. Genes encoding these enzymes were predominantly located on two genomic regions shaded in light grey (region 1) and dark grey (region 2)

${ }^{+}$A recent transcriptomic study investigated gene expression of $B$. longum subsp. infantis DSM 20088 in the presence of 2'-FL and 3'-FL, a-fucosidases that were overexpressed are indicated [34] 


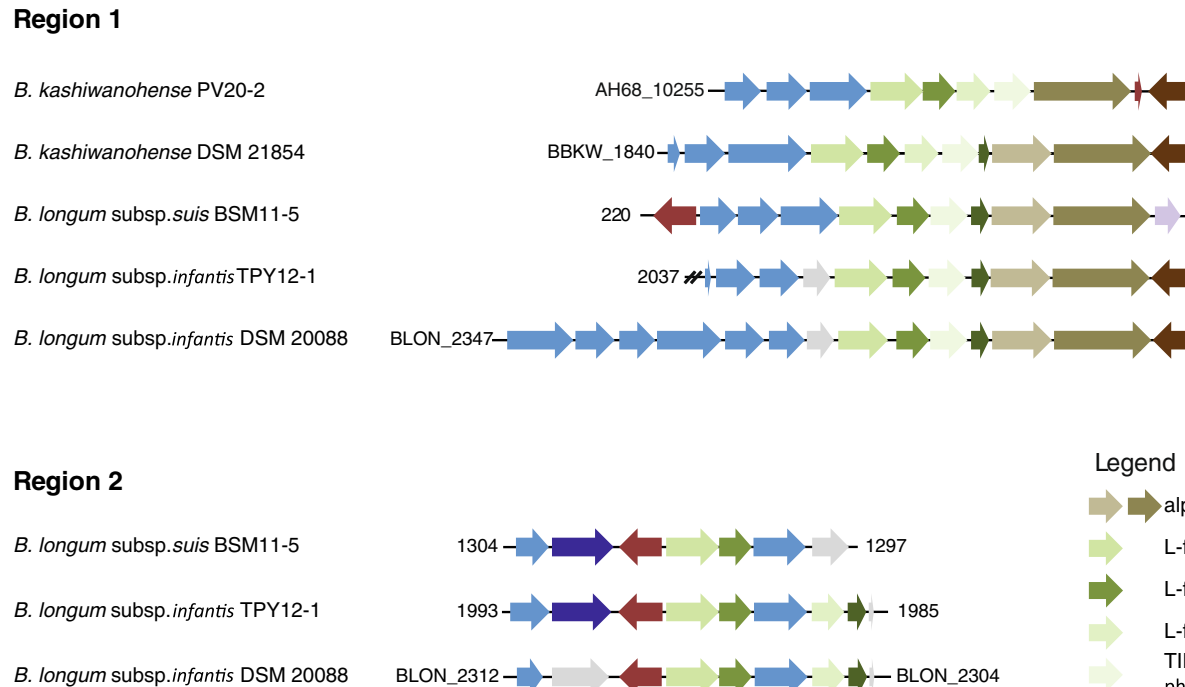

Region 2

B. longum subsp.suis BSM11-5

B. longum subsp. infantis TPY12-1

B. longum subsp.infantis DSM 20088

Legend

Fig. 3 Genomic regions encompassing genes putatively involved in fucose degradation in B. longum and B. kashiwanohense strains. The gene cluster of region 1 also contained genes encoding the a-fucosidases BLON_2335 and BLON_2336 and is part of the B. longum subsp. infantis HMO utilization operon $\mathrm{H} 1[3,11]$ (not drawn according to scale)

the B. longum subsp. infantis HMO utilization operon $\mathrm{H} 1[3,11]$. A possible L-fuconolactone hydrolase, and paralogs of fuconate dehydratase and L-fucose mutarotase were located elsewhere on the genome in close proximity to a putative fucose permease (Fig. 3).

Expression of the fuconate dehydratase of region 1, and of the putative L-2-keto-3-deoxy-fuconate hydrolase was recently reported to be upregulated when $B$. longum subsp. infantis DSM 20088 was grown in the presence of fucosyllactose providing strong support to the proposition that L-fucose is metabolized via this pathway [34].

B. kashiwanohense DSM 21854 and PV20-2 only possessed a gene segment similar to region 1 with a truncated L-fucose-mutarotase, and lacked region 2 which encompassed the fucose permease. This might be the reason why strains of $B$. kashiwanohense were not able to utilize L-fucose.

For $X$. campestris, lactate and pyruvate, but not 1,2-PD, were determined as final metabolites of fucose fermentation. Watanabe and Makino [45] however described a modified non-phosphorylated L-rhamnose pathway which would yield L-lactaldehyde from L-2-keto-3deoxyrhamnonate. The transformation of L-2-keto-3deoxyrhamnonate to L-lactaldehyde and pyruvate was catalyzed by a L-2-keto-3-deoxyrhamnonate aldolase. A possible candidate gene could be the RAST annotated 4-hydroxy-tetrahydrodipicolinate synthase possessing a structurally conserved phosphate binding motif. 4-hydroxy-tetrahydrodipicolinate synthase encoding genes were located in region 1 of all strains investigated, B. longum subsp. infantis strains possessed a paralog in region 2. 4-hydroxy-tetrahydrodipicolinate synthases reversibly catalyze the formation of 4-hydroxy-2,3,4,5tetrahydrodipicolinate from pyruvate and L-aspartate4-semialdehyde [46].

Taken together these results suggest that $B$. longum subsp. infantis TPY12-1, DSM 20088 and B. longum subsp. suis BSM11-5 metabolize fucose via a pathway with non-phosphorylated intermediates as previously described for Campylobacter sp. and X. campestris.

\section{Conclusion}

Here we observed that the ability to degrade fucosyllactose is a trait of various bifidobacteria species. We identified strains of $B$. longum subsp. infantis and an isolate of $B$. longum subsp. suis were able to degrade fucosyllactose and L-fucose to form 1,2-PD. We propose that bifidobacteria degrade $\mathrm{L}$-fucose via a pathway with non-phosphorylated intermediates as described for desoxyhexoses before. 


\section{Additional file}

Additional file 1: Figure S1. Phylogenetic tree of partial (772 nt) $16 \mathrm{~S}$ rRNA genes of strains used in this study Partial 16S rRNA gene sequences used to calculate phylogenetic tree. (DOC $2554 \mathrm{~kb}$ )

\section{Acknowledgements}

We thank Glycom A/S for supplying HMOs.

\section{Funding}

Vera Bunesova was supported by SCIEX grant 13.151

\section{Availability of data and materials}

Draft genomes were deposited at NCBI's WSG archive under accession no PRJNA339033.

\section{Authors' contributions}

VB and CS designed experiments, VB conducted experimental work, VB and CS analysed data, VB, CS and CL wrote manuscript. All authors read and approved the final manuscript.

\section{Competing interests}

The authors declare that they have no competing interests.

\section{Consent for publication}

Not applicable.

\section{Ethics approval and consent to participate}

Not applicable.

\section{Author details}

'Laboratory of Food Biotechnology, ETH Zurich, Institute of Food, Nutrition and Health, Schmelzbergstrasse 7, Zurich, Switzerland. ${ }^{2}$ Department of Microbiology, Nutrition and Dietetics, Faculty of Agrobiology, Food and Natural Resources, Czech University of Life Sciences, Prague, Czech Republic.

\section{Received: 27 August 2016 Accepted: 22 October 2016}

\section{Published online: 26 October 2016}

\section{References}

1. Bottacini F, Medini D, Pavesi A, Turroni F, Foroni E, Riley D, et al. Comparative genomics of the genus Bifidobacterium. Microbiol-Sgm. 2010; 156:3243-54.

2. Schell MA, Karmirantzou M, Snel B, Vilanova D, Berger B, Pessi G, et al. The genome sequence of Bifidobacterium longum reflects its adaptation to the human gastrointestinal tract (vol 99, pg 14422, 2002). Proc Natl Acad Sci U S A. 2005:102:9430.

3. Sela DA, Chapman J, Adeuya A, Kim JH, Chen F, Whitehead TR, et al. The genome sequence of Bifidobacterium longum subsp. infantis reveals adaptations for milk utilization within the infant microbiome. Proc Natl Acad Sci U S A. 2008;105:18964-9.

4. Duranti S, Turroni F, Lugli GA, Milani C, Viappiani A, Mangifesta M, et al. Genomic characterization and transcriptional studies of the starch-utilizing strain Bifidobacterium adolescentis 22 L. Appl Environ Microbiol. 2014;80: 6080-90.

5. Milani C, Lugli GA, Duranti S, Turroni F, Bottacini F, Mangifesta M, et al. Genomic encyclopedia of type strains of the genus Bifidobacterium. Appl Environ Microbiol. 2014;80:6290-302.

6. Pokusaeva K, Fitzgerald GF, van Sinderen D. Carbohydrate metabolism in Bifidobacteria. Genes Nutr. 2011;6:285-306.

7. Sun Z, Zhang W, Guo C, Yang X, Liu W, Wu Y, et al. Comparative genomic analysis of 45 type strains of the genus Bifidobacterium: a snapshot of its genetic diversity and evolution. PLoS One. 2015;10:e0117912.

8. Bottacini F, Ventura M, Sinderen D, Motherway MOC. Diversity, ecology and intestinal function of bifidobacteria. Microbiol Cell Fact. 2014;13:1024.

9. Liu S, Ren F, Zhao L, Jiang L, Hao Y, Jin J, et al. Starch and starch hydrolysates are favorable carbon sources for Bifidobacteria in the human gut. BMC Microbiol. 2015;15:54
10. Rockova S, Rada V, Nevoral J, Marsik P, Vlkova E, Bunesova V. Inter-species differences in the growth of bifidobacteria cultured on human milk oligosaccharides. Folia Microbiol. 2012;57:321-4.

11. LoCascio RG, Desai P, Sela DA, Weimer B, Mills DA. Broad conservation of milk utilization genes in Bifidobacterium longum subsp. infantis as revealed by comparative genomic hybridization. Appl Environ Microbiol. 2010;76:7373-81.

12. Turroni F, Duranti S, Bottacini F, Guglielmetti S, Van Sinderen D, Ventura M. Bifidobacterium bifidum as an example of a specialized human gut commensal. Front Microbiol. 2014:5:437.

13. Kunz C, Rudloff S, Baier W, Klein N, Strobel S. Oligosaccharides in human milk. Structural, functional, and metabolic aspects. Annu Rev Nutr. 2000;20: 699-722.

14. Egan M, Motherway MOC, Kilcoyne M, Kane M, Joshi L, Ventura M, van Sinderen D. Cross-feeding by Bifidobacterium breve UCC2003 during cocultivation with Bifidobacterium bifidum PRL2010 in a mucin-based medium BMC Microbiol. 2014;14:282.

15. Ruiz-Moyano S, Totten SM, Garrido DA, Smilowitz JT, Bruce German J, Lebrilla CB, et al. Variation in consumption of human milk oligosaccharides by infant gut-associated strains of Bifidobacterium breve. Appl Environ Microbiol. 2013;79:6040-9.

16. Matsuki $T$, Yahagi $K$, Mori $H$, Matsumoto $H$, Hara $T$, Tajima $S$, et al. A key genetic factor for fucosyllactose utilization affects infant gut microbiota development. Nat Commun. 2016;7:11939.

17. de Vries W, Stouthamer AH. Pathway of glucose fermentation in relation to the taxonomy of bifidobacteria. J Bacteriol. 1967;93:574-6.

18. Palframan RJ, Gibson GR, Rastall RA. Carbohydrate preferences of Bifidobacterium species isolated from the human gut. Curr Issues Intest Microbiol. 2003:4:71-5.

19. de Vries W, Stouthamer AH. Fermentation of glucose, lactose, galactose, mannitol, and xylose by bifidobacteria. J Bacteriol. 1968;96:472-8.

20. Vazquez-Gutierrez P, Lacroix C, Jaeggi T, Zeder C, Zimmerman MB, Chassard C. Bifidobacteria strains isolated from stools of iron deficient infants can efficiently sequester iron. BMC Microbiol. 2015;15:3.

21. Morita H, Nakano A, Onoda H, Toh H, Oshima K, Takami H, et al. Bifidobacterium kashiwanohense sp nov., isolated from healthy infant faeces. Int J Syst Evol Microbiol. 2011:61:2610-5.

22. Gavini F, Delcenserie V, Kopeinig K, Pollinger S, Beerens H, Bonaparte C, Upmann M. Bifidobacterium species isolated from animal feces and from beef and pork meat. J Food Prot. 2006;69:871-7.

23. Tamura K, Stecher G, Peterson D, Filipski A, Kumar S. MEGA6: molecular evolutionary genetics analysis version 6.0. Mol Biol Evol. 2013;30:2725-9.

24. Aziz RK, Bartels D, Best A, DeJongh M, Disz T, Edwards RA, et al. The RAST server: rapid annotations using subsystems technology. BMC Genomics. 2008;9:75.

25. Rodriguez-R LM, Konstantinidis KT. The enveomics collection: a toolbox for specialized analyses of microbial genomes and metagenomes. Peer J Preprints. 2016:4:e1900v1.

26. Park BH, Karpinets TV, Syed MH, Leuze MR, Uberbacher EC. CAZymes analysis toolkit (CAT): web service for searching and analyzing carbohydrateactive enzymes in a newly sequenced organism using CAZy database. Glycobiology. 2010;20:1574-84.

27. Yin Y, Mao X, Yang J, Chen X, Mao F, Xu Y. DbCAN: a web resource for automated carbohydrate-active enzyme annotation. Nucleic Acids Res. 2012 40:W445-51.

28. Turroni F, Bottacini F, Foroni E, Mulder I, Kim J-H, Zomer A, et al. Genome analysis of Bifidobacterium bifidum PRL2010 reveals metabolic pathways for host-derived glycan foraging. Proc Natl Acad Sci U S A. 2010;107:19514-9.

29. Scott KP, Martin JC, Campbell G, Mayer CD, Flint HJ. Whole-genome transcription profiling reveals genes up-regulated by growth on fucose in the human gut bacterium "Roseburia inulinivorans". J Bacteriol. 2006;188:4340-9.

30. Boronat A, Aguilar J. Metabolism of L-fucose and L-rhamnose in Escherichia coli: differences in induction of propanediol oxidoreductase. J Bacteriol. 1981;147:181-5

31. Saxena RK, Anand P, Saran S, Isar J, Agarwal L. Microbial production and applications of 1,2-propanediol. Indian J Microbiol. 2010;50:2-11.

32. Crost EH, Tailford LE, Le Gall G, Fons M, Henrissat B, Juge N. Utilisation of Mucin Glycans by the Human Gut Symbiont Ruminococcus gnavus Is StrainDependent. PLoS One. 2013:8:e76341.

33. Cocks GT, Aguilar J, Lin ECC. Evolution of $L$ 1,2 propanediol catabolism in Escherichia coli by recruitment of enzymes for $L$ fucose and $L$ lactate metabolism. J Bacteriol. 1974;118:83-8. 
34. Garrido D, Ruiz-Moyano S, Lemay DG, Sela DA, German JB, Mills DA. Comparative transcriptomics reveals key differences in the response to milk oligosaccharides of infant gut-associated bifidobacteria. Sci Rep. 2015;5:13517.

35. Gänzle MG. Lactic metabolism revisited: metabolism of lactic acid bacteria in food fermentations and food spoilage. Curr Opin Food Sci. 2015;2:106-17.

36. Engels C, Ruscheweyh H-J, Beerenwinkel N, Lacroix C, Schwab C. The common gut microbe Eubacterium hallii also contributes to intestinal propionate formation. Front Microbiol. 2016;7:713.

37. Reichardt N, Duncan SH, Young P, Belenguer A, McWilliam Leitch C, Scott $K P$, et al. Phylogenetic distribution of three pathways for propionate production within the human gut microbiota. ISME J. 2014;8:1323-35.

38. Louis P, Hold GL, Flint HJ. The gut microbiota, bacterial metabolites and colorectal cancer. Nat Rev Microbiol. 2014;12:661-72

39. Morita H, Toh H, Nakano A, Oshima K, Takagi M, Suda W, et al. Complete Genome Sequence of Bifidobacterium kashiwanohense JCM 15439(T), Isolated from Feces from a Healthy Japanese Infant. Genome Announc. 2015;3:e00255-00215.

40. Vazquez-Gutierrez P, Lacroix C, Chassard C, Klumpp J, Jans C, Stevens MJA Complete and assembled genome sequence of Bifidobacterium kashiwanohense p V20-2, isolated from the feces of an anemic Kenyan infant. Genome Announc. 2015;3:e01467-01414.

41. Sela DA, Garrido D, Lerno L, Wu S, Tan K, Eom HJ, et al. Bifidobacterium longum subsp. infantis ATCC 15697 a-fucosidases are active on fucosylated human milk oligosaccharides. Appl Environ Microbiol. 2012;78:795-803.

42. Becerra JE, Yebra MJ, Monedero V. An L-fucose operon in the probiotic Lactobacillus rhamnosus GG is involved in adaptation to gastrointestinal conditions. Appl Environ Microbiol. 2015;81:3880-8.

43. Stahl M, Friis LM, Nothaft H, Liu X, Li J, Szymanski CM, Stintzi A. L-fucose utilization provides Campylobacter jejuni with a competitive advantage. Proc Natl Acad Sci U S A. 2011;108:7194-9.

44. Yew WS, Fedorov AA, Fedorov EV, Rakus JF, Pierce RW, Almo SC, Gerlt JA. Evolution of enzymatic activities in the enolase superfamily: L-fuconate dehydratase from Xanthomonas campestris. Biochemistry. 2006;45:14582-97.

45. Watanabe S, Makino K. Novel modified version of nonphosphorylated sugar metabolism - An alternative L-rhamnose pathway of Sphingomonas sp. FEBS J. 2009;276:1554-67.

46. Scapin G, Blanchard JS. Enzymology of bacterial lysine biosynthesis. Adv Enzymol Relat Areas Mol Biol. 1998;72:279-324.

\section{Submit your next manuscript to BioMed Central and we will help you at every step:}

- We accept pre-submission inquiries

- Our selector tool helps you to find the most relevant journal

- We provide round the clock customer support

- Convenient online submission

- Thorough peer review

- Inclusion in PubMed and all major indexing services

- Maximum visibility for your research

Submit your manuscript at www.biomedcentral.com/submit 